Review

\title{
Supercritical solvent impregnation of ophthalmic drugs on chitosan derivatives
}

\author{
Mara E.M. Braga ${ }^{\text {a } *}$, Maria T. Vaz Pato ${ }^{a}$, Hélio S.R. Costa Silva ${ }^{b}$, Elisabeth I. Ferreira ${ }^{b}$, \\ Maria H. Gil ${ }^{a}$, Catarina M.M. Duarte ${ }^{c}$, Hermínio C. de Sousa ${ }^{a}$ \\ ${ }^{a}$ Department of Chemical Engineering, University of Coimbra, Pólo II, \\ Rua Sílvio Lima, 3030-790 Coimbra, Portugal \\ ${ }^{\mathrm{b}}$ Faculdade de Ciências Farmacêuticas, USP, Av. Professor Lineu Prestes 580, \\ Bloco 13, 05508-900 São Paulo, SP, Brazil \\ ${ }^{\mathrm{c}}$ Nutraceuticals and Delivery Laboratory, ITQB/IBET, \\ Aptd. 12, 2780 Oeiras, Portugal
}

Received 30 March 2007; received in revised form 20 September 2007; accepted 11 October 2007

\begin{abstract}
In this work, three chitosan derivatives ( $N$-carboxymethyl chitosan (CMC), $N$-carboxybutyl chitosan (CBC) and $N$-succinyl chitosan (SCC)) were impregnated with flurbiprofen (an anti-inflammatory drug) and timolol maleate (an anti-glaucoma drug), using a supercritical solvent impregnation (SSI) technique (and employing high pressure $\mathrm{CO}_{2}$ and $\mathrm{CO}_{2}+$ EtOH mixtures) in order to develop hydrogel-type ophthalmic drug delivery applications. Impregnation experiments were carried out from 9.0 up to $14.0 \mathrm{MPa}$, and at 303.0, 313.0 and $323.0 \mathrm{~K}$. The resulting polymeric drug delivery systems, as well as other polymeric samples processed in $\mathrm{CO}_{2}$, were characterized by FTIR spectroscopy and scanning electron microscopy (SEM). Drug release kinetics studies were performed for all prepared systems. The effects of impregnation pressure and temperature on the release kinetics results were studied and compared to the traditional soaking impregnation method. For the same operational conditions, results confirmed that the three different (chemically and physically) polymeric structures conditioned the impregnation and the drug release processes. Despite the final released drug mass is always the result of the employed operational impregnation conditions and of the very complex relative specific interactions that may occur between all species present in the system (drugs, polymers, $\mathrm{CO}_{2}$ and ethanol), results showed that, for $\mathrm{N}$-carboxymethyl chitosan, the predominant effects in the impregnation process seemed to be the solubility of drugs in $\mathrm{CO}_{2}$ and in $\mathrm{CO}_{2}+\mathrm{EtOH}$ mixtures, as well as the swelling and plasticizing effect of $\mathrm{CO}_{2}$ and ethanol on the polymer. Finally, the SSI method proved to be a more efficient and "tunable" impregnation process than the traditional impregnation of drugs by a soaking method. Therefore, and using this "tunable" SSI method, these $\mathrm{N}$-chitosan derivatives-based ophthalmic drug delivery systems can be easily and efficiently prepared taking in consideration the desired drug levels according to patients needs.
\end{abstract}

(C) 2007 Elsevier B.V. All rights reserved.

Keywords: $N$-chitosan derivatives; Ophthalmic drug delivery systems; Supercritical solvent impregnation (SSI); Flurbiprofen; Timolol maleate

\section{Contents}

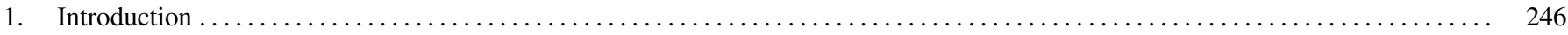

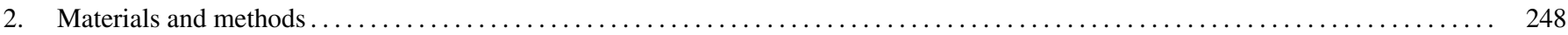

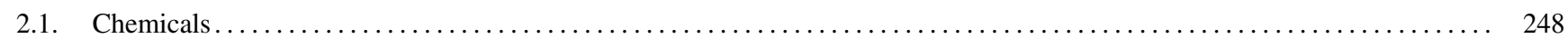

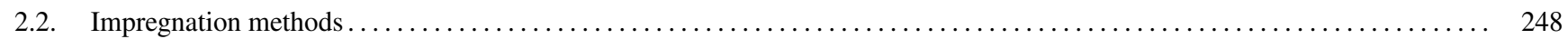

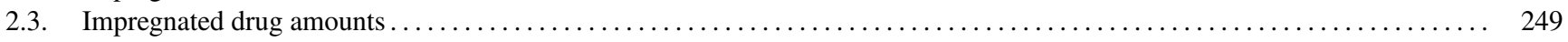

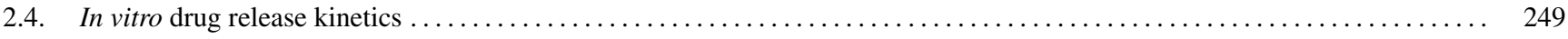

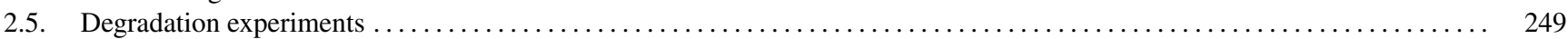

\footnotetext{
* Corresponding author. Tel.: +351 239798 758; fax: +351 239708703 .

E-mail address: marabraga@eq.uc.pt (M.E.M. Braga).
} 


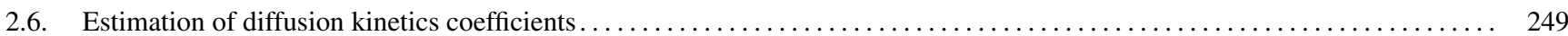

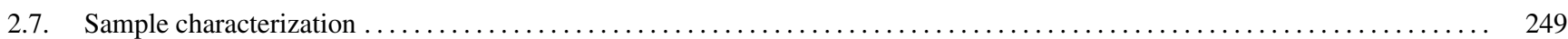

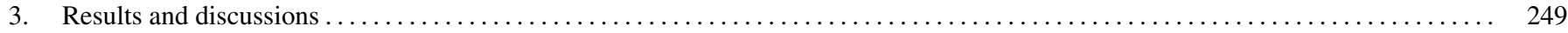

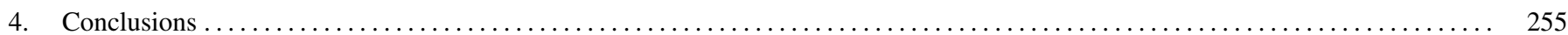

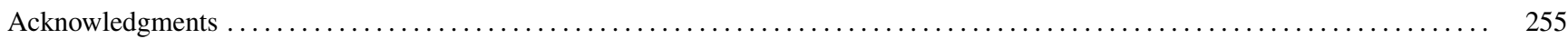

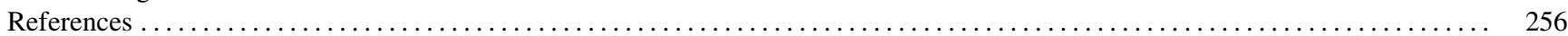

\section{Introduction}

Some ocular diseases are very common in the ageing population namely cataracts, glaucoma, diabetic retinopathy and age-related macular degeneration (AMD) [1]. Commonly, medicines are applied on the eye surface in order to treat eye's outer surface diseases like infections or to provide intraocular treatment through the cornea as glaucoma or AMD. However, typical topical current therapeutic procedures and formulations present several limitations, like poor drug bioavailability and the possibility of occurrence of systemic toxicity [2].

Poor ocular drug bioavailability is owed essentially to the relative impermeability of the corneal membrane, to blinking and tear dynamics, and to nasolacrimal drainage. Generally, the delivery of ocular drugs to the eye posterior segment is reduced by the same factors that are also responsible for poor ocular bioavailability and also by the blood-retinal barrier which limits the intravenous route in posterior drug delivery [2-4]. Poor drug absorption across mucosal membranes is due essentially to the drug/membrane relative hydrophobic/hydrophilic natures. Although, some ophthalmic drugs may present an important therapeutic value for a specific pathology, these relative and different natures may reduce or even impede drug membrane permeability and, consequently, their therapeutic value is lost $[5,6]$. Moreover, tear dynamics and nasolacrimal duct drainage is also the major way of entry into the circulatory system of potent ocular drugs applied by topical administration. This may cause undesired and toxic systemic side-effects [7-9].

Pulse-drug delivery is a recurrent but undesired pharmacokinetic characteristic associated with topical eye drops drug formulations. Normally, in these systems, only less than 1-4\% of the instilled dose reaches the aqueous humor. As a consequence, and despite the fact of causing a potential risk of systemic toxicity, clinicians are forced to recommend frequent drug dosing, at high concentrations, in order to avoid the poor drug bioavailability at the posterior segment of the eye $[10,11]$. Nevertheless, and despite their inherent disadvantages and associated risks, these conventional dosage forms account for almost $90 \%$ of the commercially available therapeutic ophthalmic products mostly because of their favorable costs, simplicity of formulation, selfapplication and good acceptance by patients.

To overcome these problems, and in recent years, a considerable effort has been made in order to develop capable ophthalmic controlled drug release systems (CDR's), focusing essentially on two main objectives: (i) to find or make newer, more effective and safer drug molecules for the various ocular conditions and diseases and (ii) to improve the already existing ocular dosage forms and to exploit newer and more efficient delivery systems in order to improve ocular bioavailability of already existing drug molecules. Actual trends in ocular therapeutics and ophthalmic drug delivery indicates that the existing dosage forms may and probably will be substituted by new CDR's, which can offer improved biopharmaceutical properties, with a better capability to deliver therapeutic agents to the targeted receptors in the eye, and in a more predictable and reproducible way [12].

Presently, there are several proposed ophthalmic CDR's designed to treat most of the common diseases of the eye, some of them already are commercially available, like: enhanced topical administration of water-soluble eye drops; water-insoluble drugs in ointments; polymeric hydrogels; in situ activated gelling systems; mucoadhesive and bioadhesive hydrogels; colloidal systems, penetration enhancers; collagen shields; prodrugs and ocular inserts [2-4,7].

Hydrogels are highly swollen hydrophilic polymer networks which increase their volumes by absorbing large amounts of water or aqueous solutions [13]. Hydrogel formulations usually prolong the residence time of drugs at the absorption site, maintaining drug release and improving drug bioavailability for convenient periods [14]. Different ophthalmic hydrogel formulations like, for example ophthacoil (a drug-loaded adherent hydrogel coating on a thin metallic wire), were developed and are commercially available as an alternative to topical eye drop administration for sustained drug delivery $[15,16]$. Other ophthalmic hydrogel-based devices like therapeutic contact lenses (TCL), intraocular lenses, glaucoma filtration implants, keratoprostheses, intracorneal implants, scleral buckles and viscoelastic replacement agents are also commonly used in ophthalmology [2,7,12,13,17-19]. These hydrogel devices may be composed by synthetic (or natural) biocompatible and/or biodegradable polymers, copolymers, polymeric blends or also by polymeric composites.

Chitosan-based and chitosan derivatives-based hydrogels already showed a great potential to be used as CDR's for several pharmaceutical and biomedical applications [2,13,14,20,21] including ophthalmic CDR's. Chitosan is an abundant and natural polysaccharide which presents some interesting and useful properties such as biocompatibility, biodegradability, non-toxicity, adsorption and adhesion properties and the ability to interact with different substances (like hydrophilic and hydrophobic drugs) [13,22,23]. These characteristics are extremely important for medical and pharmaceutical applications, namely for the development controlled drug release devices [13,24,25]. For ocular applications, it is also recognized that chitosan-based formulations present a prolonged precorneal residence time, an ability to increase solution viscosity and excellent mucoadhesive properties [26,27]. 
Most of the chitosan functional biological properties are related to molecular weight, charge density and distribution, degree of deacetylation and to the $\mathrm{pH}$ value of the media in which they can be placed into. Consequently, these factors can restrain some chitosan applications as drug delivery systems $[13,14]$. For example, chitosan have limited solubility at $\mathrm{pH}$ above 6 (the physiological $\mathrm{pH}$ of the buccal cavity) and some incompatibility with anionic drugs [28].

As a result, usually there is a practical necessity to develop several chitosan derivatives with improved solubility/nonsolubility, at different $\mathrm{pH}$ values, or, for example, to obtain a better permeability to anionic drugs and to avoid the undesired formation of drug-polymer complexes [28,29]. This can be done by introducing some specific chemical modifications into the chitosan chain molecule. These "tailored" modifications may change the polymeric solubility/non-solubility and biodegradability/biocompatibility nature, the polymeric ability to interact with drugs or with other biomolecules as enzymes, for example, and the kinetics of drug release for any new or particular envisaged controlled drug delivery application. For example, Sandri et al. [28], studied different chitosan derivatives as acyclovir penetration enhancers adding the drug to several modified chitosans: 5-methyl-pyrrolidinone chitosan (MPC), low molecular weight chitosans, a partially reacetylated chitosan and chitosan hydrochloride. In this study, MPC presented the best mucoadhesive and penetration/permeation enhancement properties. Thanou et al. [29] studied, the use of high viscosity chitosan (HCS) and low viscosity (LCS) chitosan as well as mono- $N$-carboxymethyl chitosan (MCC) with low and high grade viscosities (LMCC and HMCC). On other work, the permeation and adsorption of low molecular weight heparin (LMWH) was increased using $N$-carboxymethylated chitosan via intestinal epithelia [30]. Other chitosan derivative, trimethyl chitosan chloride (TMC), showed an increased peptide intestinal absorption and bioavailability for buserelin and octreotide analogs across intestinal epithelia [30]. In addition to $N$-carboxymethyl chitosan (CMC), other $N$-carboxyalkyl chitosans like $N$-carboxybutyl chitosan (CBC) and succinyl chitosan (SCC) (Fig. 1) had been studied as polymeric drug carriers [31-33].

Polymeric dispersed drug CDR's are usually prepared by two conventional methods. A first method consists in mixing the drug, or drugs, in the polymer synthesis reactive mixture, containing monomers, co-monomers, cross-linkers, initiators, etc. Drugs can be soluble or insoluble in this mixture. Then, the resulting mixture is polymerized, for example, by a thermal or photochemical route. A second method consists in immersing and soaking the polymeric particles/articles, previously synthesized, into a solution, or dispersion, containing the drugs to impregnate/infuse. Usually an aqueous solution, or dispersion, is used but organic solutions or dispersions can also be employed, depending essentially on drug and polymer solubility or on other considerations like, for example, solvent toxicity and solvent facility to be removed/evaporated [34-39]. However, these methods present several disadvantages, like the use of sometimes toxic organic solvents, which have to be removed by heating, undesired drug reactions, drug and polymer photochemical and thermal degradation, low incorporation yields and heterogeneous drug dispersion.

Drugs may also be impregnated by dissolving them in compressed high volatile fluids like supercritical carbon dioxide, at temperatures and pressures near or above their critical temperatures and pressures, and contacting the resulting mixture with the polymeric matrixes to be infused. In these conditions, the compressed fluid can act also as a swelling and plasticizer agent for polymers, helping drugs' diffusion into them. This happens because, and despite the usually low polymer solubility in $\mathrm{CO}_{2}$, the sorption and solubility of $\mathrm{CO}_{2}$ in some polymers is considerably high, promoting polymer swelling and changing polymeric mechanical properties by a plasticization effect [40-42].

This recent technique, presents several advantages for the development of drug impregnated polymeric materials which can be used as drug delivery systems for many biomedical applications. It is called supercritical solvent impregnation (SSI) [40-43] and permits the drug impregnation of a great part of polymeric matrixes. Furthermore, some interesting hydrophobic drugs, which can not be impregnated by aqueous solution/suspension soaking, can be incorporated by this method. Drug loading and drug depth penetration can be considered as a "tunable" process since it can be performed by controlling the depressurization step (which can be performed at several rates), the time of impregnation or by changing the solvent density (and consequently the drug solubility in it) by pressure and temperature control, in opposition of conventional impregnation processes [40-42]. Furthermore, and in most cases, it can be carried properly in order to not alter and/or damage polymeric materials physical, chemical, and mechanical properties and without degrading drugs, additives and polymers. It also may permit to have previously prepared polymeric matrixes and, later, impregnate them with the desired drugs,

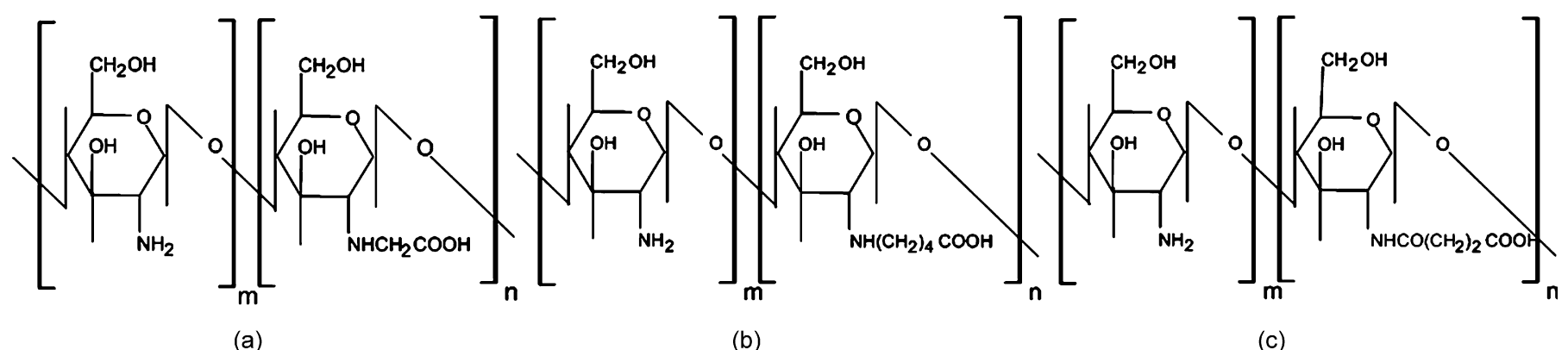

Fig. 1. Structural formula of employed chitosan derivatives: (a) $N$-carboxymethyl chitosan; (b) $N$-carboxybutyl chitosan and (c) $N$-succinyl chitosan. 


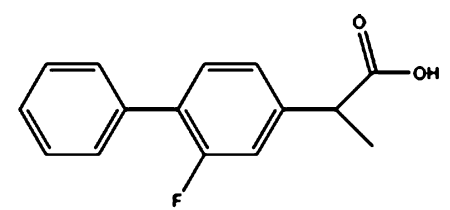

Flurbiprofen

Molecular Formula: $\mathrm{C}_{15} \mathrm{H}_{13} \mathrm{FO}_{2}$

Molecular Weight: $244.261 \mathrm{gmol}^{-1}$<smiles>CCCN(CC(O)COc1nsnc1N1CCOCC1)C(C)C</smiles>

Timolol Maleate

Molecular Formula: $\mathrm{C}_{17} \mathrm{H}_{28} \mathrm{~N}_{4} \mathrm{O}_{7} \mathrm{~S}$

Molecular Weight: $432.493 \mathrm{gm} \mathrm{ol}^{-1}$

Fig. 2. Structural formula of impregnated drugs.

according to desired applications and patients' needs and leaving no harmful solvent residues.

Several ophthalmic drugs were already incorporated into polymeric matrixes with the intention of preparing ophthalmic CDR's systems and are reported in the literature: for example, cortisone and retinol [44], ibuprofen [45], pilocarpine [46] and indomethacin [47]. Some systems were already prepared using the SSI technique and using $\mathrm{CO}_{2}$ as the high pressure solvent $[48,45,49]$. Some ophthalmic drugs as timolol maleate and flurbiprofen, a beta adrenergic blocker, and, a non-steroidal analgesic/anti-inflammatory, respectively (Fig. 2) had also been used as active principles in several polymeric-based (acrylates and chitosan/carbopol mixtures, respectively) ocular CDR's prepared by reverse phase evaporation [50] and by quasi-emulsion solvent diffusion technique [51].

The solubility of these two solid drugs was already measured in carbon dioxide. The maximum solubility for flurbiprofen was found to be $0.90 \mathrm{~g} / \mathrm{L}$, at $323 \mathrm{~K}$ and 234 bar [52]. For timolol maleate the maximum $\mathrm{CO}_{2}$ solubility was determined as $0.56 \mathrm{~g} / \mathrm{L}$ [53]. The minimum amount of flurbiprofen to be kept in the eye must be, at least, $0.03-0.15 \mu \mathrm{g}$, the therapeutic limit in order to prevent and treat inflammatory processes. Its chronic toxicity is $5 \mathrm{mg} /(\mathrm{kg}$ day) for 26 weeks [54], based on data obtained at clinical essays in baboons. For timolol maleate, the maximum recommended therapeutic dose (MRTD) is $1 \mathrm{mg} /(\mathrm{kg}$-bw day) [55].

The main objectives of this work were to study the impregnation of two ophthalmic drugs (flurbiprofen and timolol maleate) into three chitosan derivatives: $N$-carboxymethyl chitosan (CMC), $N$-carboxybutyl chitosan (CBC) and $N$-succinyl chitosan (SCC), using the supercritical solvent impregnation (SSI) methodology employing high pressure $\mathrm{CO}_{2}$ and $\mathrm{CO}_{2}+\mathrm{EtOH}$ mixtures, in order to prepare hydrogel-type drug delivery systems for ophthalmic applications. Other goals were to study the pressure and temperature effects on the resulting CDR's systems and to compare the employed SSI method with the conventional polymer soaking method.

\section{Materials and methods}

\subsection{Chemicals}

The three chitosan derivatives used in this work: $N$-carboxymethyl chitosan (CMC), $N$-carboxybutyl chitosan (CBC) and
$\mathrm{N}$-succinylchitosan (SCC) were prepared according to Silva [56], Fig. 1. Employed ophthalmic drugs were: flurbiprofen (97\%, Sigma-Aldrich, CAS [5104-49-4], Germany) and timolol maleate ( $\geq 98 \%$, Sigma-Aldrich, CAS [26921-17-5], Germany), Fig. 2. Employed solvents were: carbon dioxide (99.998\%, Praxair, Spain) and ethanol (99.8\%, Riedel-de-Haën). Physiological serum (sodium chloride isotonic solution, $\mathrm{pH} 6,154 \mathrm{mEq}$ for $\mathrm{Na}+$ and $\mathrm{Cl}-$, Osm $\sim 285 \mathrm{mOsm} / \mathrm{kg}$, Fresenius Kabi, Portugal) was used as drug release media.

\subsection{Impregnation methods}

The employed supercritical impregnation apparatus is described by Patent EP 1611877 A1 (Unit I), and it is presented at Fig. 3 [57]. This unit is comprised by a compressed airoperated $\mathrm{CO}_{2}$ liquid pump, a visual stainless steel impregnation cell (with approximately $10 \mathrm{~cm}^{3}$ of internal volume), equipped with sapphire windows, a thermostatic controlled water bath and a magnetic stirring plate as an auxiliary tool to homogenize the high pressure mixture (drug $+\mathrm{CO}_{2}$ or drug $+\mathrm{CO}_{2}+$ cosolvent). Ethanol (EtOH), 5\%, mol, was used as the cosolvent and with the intention of increase timolol maleate's solubility in supercritical carbon dioxide [53]. Several supercritical solvent impregnation (SSI) experiments were performed in order to study the effects of operational temperature at $\sim 303,313$ and $323 \mathrm{~K}$ and pressure from $\sim 9$ up to $14 \mathrm{MPa}$ ) for the systems $\mathrm{CMC}+$ flurbiprofen and $\mathrm{CMC}+$ timolol maleate.

Average depressurization average rates were $0.29 \pm$ $0.01 \mathrm{MPa} / \mathrm{s}$, for polymer + flurbiprofen systems, and $0.29 \pm$ $0.02 \mathrm{MPa} / \mathrm{s}$ for polymer+timolol maleate systems. Higher

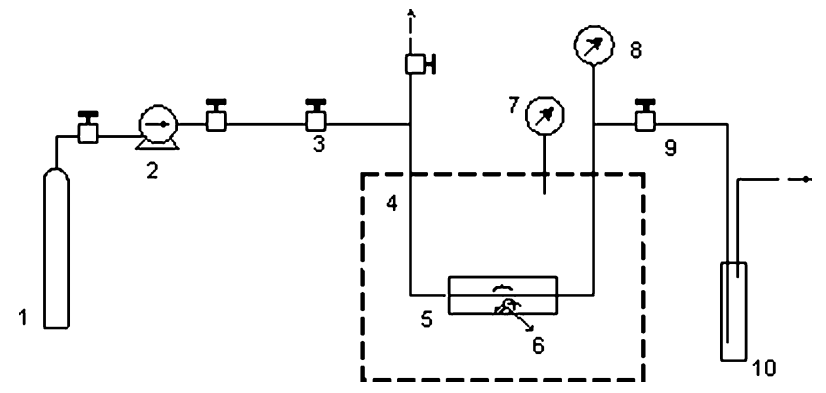

Fig. 3. Schematic diagram of the experimental supercritical impregnation apparatus: (1) $\mathrm{CO}_{2}$ reservoir; (2) high pressure $\mathrm{CO}_{2}$ pump; $(3,9)$ valves; (4) water bath; (5) high pressure stainless steel impregnation cell; (6) magnetic stirrer; (7, 8) thermometer and pressure transducer and (10) glass trap. 
depressurization rates may cause the "explosion" of polymeric samples and, consequently, may destroy their structures.

The SSI method consists in introduce the $\mathrm{CO}_{2}$ into the sealed high pressure impregnation cell, previously charged with the polymeric sample (around $0.004-0.015 \mathrm{~g}$ of polymer), the drug (and the cosolvent, when used), at the pre-established process temperature and pressure. Magnetic stirring was always employed in order to solubilize and homogenize the drug in the compressed fluid $\left(\mathrm{CO}_{2}\right.$ or mixture of $\left.\mathrm{CO}_{2}+\mathrm{EtOH}\right)$. The amount of drug was established taking in consideration its solubility (saturated environment) at the operational conditions. The amount of added cosolvent was also calculated taking into consideration the desired cosolvent concentration and the operational temperature and pressure conditions. SSI experiments were carried out during $1 \mathrm{~h}$. After this period, the compressed fluid, or the mixture of compressed fluid and cosolvent, was removed by slow expansion in order not to alter or damage the polymeric samples. Impregnated samples were then recovered in a dry final state.

Conventional drug soaking experiments were performed in a glass vial, containing the polymeric sample to be impregnated, during $1 \mathrm{~h}$, in saturated drug + physiological serum solutions and at ambient conditions ( $0.1 \mathrm{MPa}, 294 \mathrm{~K})$.

\subsection{Impregnated drug amounts}

The amounts of impregnated drugs were quantified gravimetrically, before and after impregnation experiments, and compared to the results obtained by the drug release kinetics spectrophotometric method (to be described further on). The polymeric flurbiprofen and timolol maleate residual contents (after drug release experiments) were quantified by fluorine and sulphur, respectively, analysis using Ion Chromatography (Waters, 431 model, USA) with conductivity detector (Millipore, USA), IC-Pak A anions column and borate/gluconate as eluent, at $2.93 \mathrm{MPa}$, conductivity of $319 \mu \mathrm{S}$ and flow rate of $1 \mathrm{~mL} / \mathrm{min}$.

\subsection{In vitro drug release kinetics}

Drug release kinetics studies were performed for all prepared systems using a spectrophotometer (Jasco, models 530 and 550, Japan), at 247 and $298 \mathrm{~nm}$, for the release of flurbiprofen and timolol maleate, respectively. Release experiments were carried out during $8 \mathrm{~h}$, in order to simulate the envisaged ophthalmic use.

Impregnated polymers were immersed in physiological serum, at $310 \mathrm{~K}$, and an aliquot $(1.6 \mathrm{~mL})$ of the released drug solution was removed and analyzed, with or without renovation of the release medium with fresh serum. The release medium renovation was done, for each experimental release point, by removing an aliquot $(1.6 \mathrm{~mL})$ for $\mathrm{UV}$ analysis and by adding the same volume of fresh serum to the release medium. Drug concentration was calculated using previously determined drug calibration curves [57-59].

The operational central point of experiments was considered to be $11 \mathrm{MPa}$ and $313 \mathrm{~K}$ (obtained for $\mathrm{CMC}+$ timolol maleate experiments) and, at these conditions, triplicate assays were performed in order to obtain the experiments standard deviation ( $\pm 0.012 \mathrm{mg}$ of $\mathrm{drug} / \mathrm{mg}$ of polymer).

\subsection{Degradation experiments}

Non-impregnated CMC samples were also tested in terms of their ability to degrade over time in the physiological serum solution. CMC samples were pressurized, for $1 \mathrm{~h}$, with supercritical $\mathrm{CO}_{2}$ at $12 \mathrm{MPa}$ and $313 \mathrm{~K}$. These samples were then immersed and maintained in physiological serum for $168 \mathrm{~h}$ (one week). After this period, the physiological serum was analyzed spectrophotometrically (at 200-800 nm) in order to detect the presence of substances generated from polymer degradation and/or solubilization.

\subsection{Estimation of diffusion kinetics coefficients}

Drug release kinetics coefficients were estimated from the flurbiprofen/polymers drug release kinetics studies. Curves were fitted using Eq. (1), where $M_{t}$ and $M_{\infty}$ represent the amounts of flurbiprofen released at time $t$ and after infinite time, respectively, $n$ is the diffusion exponent and $k$ the diffusion kinetic constant $[60,61]$.

$\frac{M_{t}}{M_{\infty}}=k \cdot t^{n}$

\subsection{Sample characterization}

Obtained controlled drug delivery systems were chemically and optically characterized by FTIR-ATR spectroscopy (Magma-IR Spectrometer 750, Nicolet Instrument Corp., Wisconsin, USA; ATR, Golden Gate MK II, Specac, USA) DTGS $\mathrm{KBr}$ detector, at 32 scans and $4 \mathrm{~cm}^{-1}$ of resolution) and by Scanning Electron Microscopy (SEM) (Jeol, JSM-5310 model, Japan), at $25 \mathrm{kV}$. Samples were coated with gold, approximately $300 \AA$, in an argon atmosphere, and analyzed before and after the polymer impregnation experiments.

\section{Results and discussions}

The drug release triplicate assays, which were performed at an operational central point (11 MPa and $313 \mathrm{~K}$ ) for the timolol maleate $+\mathrm{CMC}$ system, presented in vitro drug release average values with a curve amplitude of 3\% (in mass) until the second experimental point. After this point, curve amplitude was almost constant, $1-2 \%$ (in mass). These amplitude values were considered to be valid for all studied systems (Table 1).

Fig. 4 shows the accumulated flurbiprofen mass release profiles for the three employed chitosan derivatives (CMC, CBC and SCC), impregnated for $1 \mathrm{~h}$ at $12 \mathrm{MPa}$ and $313 \mathrm{~K}$ by SSI. As shown, and after $8 \mathrm{~h}$ of release studies, the accumulated released amount of flurbiprofen was found to be higher for CMC, followed by SCC and CBC $(0.125,0.081$ and $0.053 \mathrm{mg}$ flurbiprofen $/ \mathrm{mg}$ polymer, respectively). These in vitro release studies were performed without the renovation of the releasing 
Table 1

Accumulated drug release results in physiological serum, obtained after $8 \mathrm{~h}$ of drug release from SSI and soaking flurbiprofen and timolol maleate impregnated chitosan derivatives (CMC, CBC and SCC). For Flurbiprofen, drug release was performed without physiological serum renovation. For timolol maleate, drug release was performed with physiological serum renovation

\begin{tabular}{|c|c|c|c|c|c|c|c|c|c|}
\hline \multirow[t]{2}{*}{ Impregnation process } & \multicolumn{9}{|c|}{ Timolol maleate $(5 \%)(\mathrm{mg} / \mathrm{mg}$ polymer $)$} \\
\hline & \multicolumn{2}{|c|}{$\sim 0.1(\mathrm{MPa})$} & 9 (MPa) & \multicolumn{2}{|c|}{$10(\mathrm{MPa})$} & $11(\mathrm{MPa})$ & 12 (MPa) & 13 (MPa) & $14(\mathrm{MPa})$ \\
\hline \multicolumn{10}{|l|}{ CMC polymer } \\
\hline $\mathrm{SSI}\left(40^{\circ} \mathrm{C}\right)$ & \multicolumn{2}{|l|}{-} & 0.394 & 0.462 & \multicolumn{2}{|c|}{$0.531 \pm 0.012$} & 0.550 & 0.800 & 0.849 \\
\hline $\operatorname{SSI}\left(50^{\circ} \mathrm{C}\right)$ & \multicolumn{2}{|l|}{-} & 0.086 & 0.203 & \multicolumn{2}{|c|}{0.461} & 0.590 & \multirow{2}{*}{$\begin{array}{l}0.527 \\
-\end{array}$} & 0.445 \\
\hline Soaking & \multicolumn{2}{|l|}{0.674} & - & - & \multicolumn{2}{|c|}{-} & - & & - \\
\hline & \multicolumn{7}{|c|}{ CMC polymers } & \multirow{2}{*}{$\begin{array}{l}\text { CBC polymers } \\
12(\mathrm{MPa})\end{array}$} & \multirow{2}{*}{$\begin{array}{l}\text { SCC polymers } \\
12(\mathrm{MPa})\end{array}$} \\
\hline & $\sim 0.1(\mathrm{MPa})$ & $9(\mathrm{MPa})$ & $10(\mathrm{MPa})$ & $11(\mathrm{MPa})$ & $12(\mathrm{MPa})$ & $13(\mathrm{MPa})$ & $14(\mathrm{MPa})$ & & \\
\hline $\mathrm{SSI}\left(30^{\circ} \mathrm{C}\right)$ & - & 0.080 & - & - & - & - & - & - & - \\
\hline SSI $\left(40^{\circ} \mathrm{C}\right.$ & - & 0.035 & 0.035 & 0.097 & 0.125 & 0.147 & - & 0.053 & 0.081 \\
\hline $\operatorname{SSI}\left(50^{\circ} \mathrm{C}\right)$ & - & 0.017 & 0.043 & 0.112 & 0.034 & 0.079 & - & & \\
\hline
\end{tabular}

media (without the addition of a "fresh" volume of physiological serum). All impregnated samples presented almost the same drug release profile, a typical biphasic release pattern: (i) a diffusional period with an initial increase probably as a result of the rapid release caused by drugs deposited on and near the polymeric surface and which is related to the total surface of polymers and/or to its high porosity; (ii) a swelling phase, a period that occurs before the disintegration/dissolution of the polymers (which was not observed, because the degradation/solubilization tests indicated that the physiological serum solution did not degrade or solubilize the employed polymers after $168 \mathrm{~h}$ of contact, at ambient conditions). However, while flurbiprofen release from $\mathrm{CBC}$ reached the equilibrium at approximately $30 \mathrm{~min}$; for $\mathrm{CMC}$ and SCC around $2.5 \mathrm{~h}$ were required to reach equilibrium.

The observed initial burst release profiles can be an indication that the impregnated drug was mainly located at the polymer surface or near it. And the different initial profiles obtained would then be the result of the different impregnation efficiencies due to the different interactions between $\mathrm{CO}_{2}$, drugs and the three employed chitosan derivatives. Short impregnation periods can also be responsible for low depth impregnation but the impregnation duration was kept constant for these experiments. However,

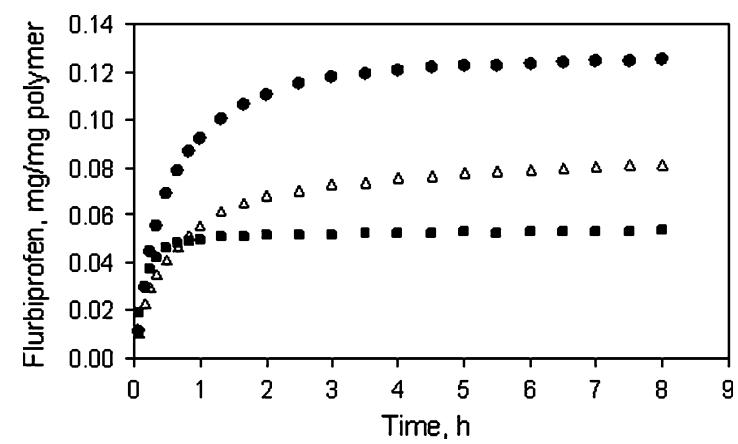

Fig. 4. Accumulated flurbiprofen mass released from chitosan derivatives, impregnated at $12 \mathrm{MPa}$ and $40^{\circ} \mathrm{C}$ by SSI: $\mathrm{CMC} ; \triangle \mathrm{SCC}$ and $\boldsymbol{\mathrm { CBC }}$. different release profiles can also be due to other factors related with the release experiments and not just to the impregnation process like, for example, polymer/drug/release medium physical and chemical properties and interactions and to polymer swelling. Therefore, this is an evidence that, at the same impregnation and release conditions, the three different (chemically and physically) polymeric structures somehow conditioned the impregnation and the drug release processes.

The conventional soaking method, employed for the same system (CMC + flurbiprofen) and soaking the polymeric sample for $1 \mathrm{~h}$ at ambient conditions ( $\sim 0.1 \mathrm{MPa}$ and $294 \mathrm{~K})$, showed an accumulated released drug amount of $0.074 \mathrm{mg}$ flurbiprofen $/ \mathrm{mg}$ of CMC (Table 1), which is almost half of the observed release for the sample impregnated by SSI at $12 \mathrm{MPa}$ and $313 \mathrm{~K}$. However, this observed more efficient SSI impregnation does not occur for all the employed operational temperature and pressure conditions and this subject will be discussed in detail further on. Table 1 also presents other results which show that, for the CMC derivative, SSI is a "tunable" impregnation process, i.e., varying the operational pressure and temperature conditions will result in the impregnation of different drug amounts which will lead to different drug released amounts (from 0.017 to $0.147 \mathrm{mg}$ of flurbiprofen/mg of CMC). This is an evident advantage of the SSI technique. Furthermore, in some cases and for strongly hydrophobic drugs, it is not possible to use drug aqueous soaking solutions and the use of organic solvents is not recommendable for the development of CDR's applications.

Fig. 5 shows the absolute flurbiprofen mass released, as a function of release time, for the three used chitosan derivatives. It can be seen that the diffusional period may be extended over time until the released drug mass become almost constant: around $1 \mathrm{~h}$ ( 1-2 $\mu \mathrm{g}), 3 \mathrm{~h}(\sim 3-5 \mu \mathrm{g})$ and $4 \mathrm{~h}(\sim 3-6 \mu \mathrm{g})$, for CBC, SCC and $\mathrm{CMC}$, respectively, and above the flurbiprofen therapeutic limit. The knowledge of these values is very important to develop efficient CDR devices, capable to keep drug concentrations between therapeutic and toxic limits. The mass variation showed in the 


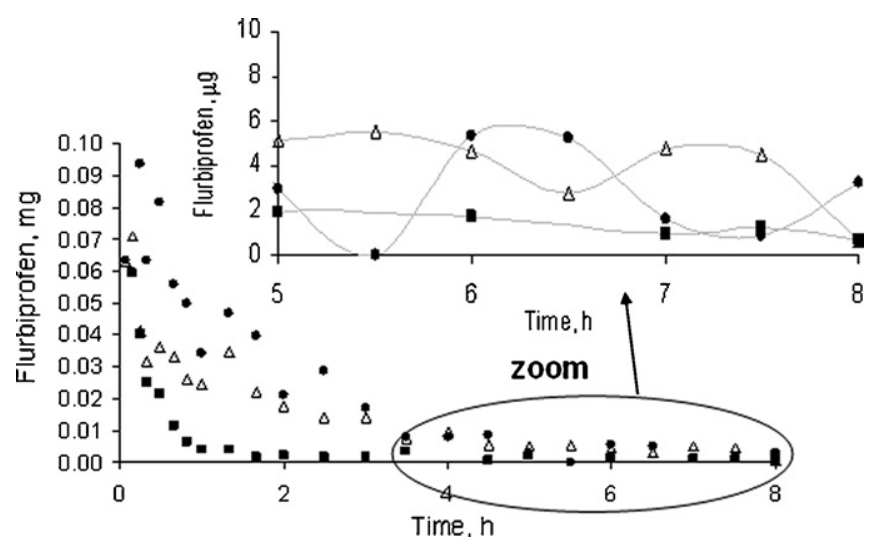

Fig. 5. Flurbiprofen mass released from chitosan derivatives, impregnated at $12 \mathrm{MPa}$ and $40^{\circ} \mathrm{C}$ by SSI: $(\bigcirc) \mathrm{CMC} ;(\triangle)$ SCC and $(\boldsymbol{\square}) \mathrm{CBC}$.

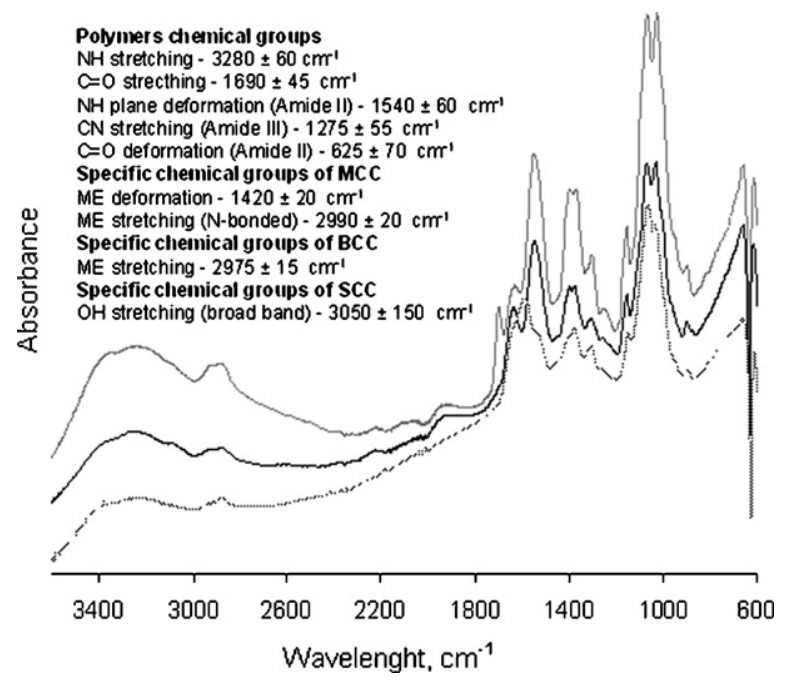

Fig. 6. FTIR analysis of chitosan derivatives before impregnation: (-) CBC; (-) SCC and (...) CMC.

zoomed part of Fig. 5 is still due to small fluctuations in drug release and not to any experimental uncertainties related to the method detection limit.

FTIR analysis (Fig. 6) shows the different spectrum profiles for the three chitosan derivatives. A characteristic peak for these polymers appears at the same wavelength $\left(1541 \mathrm{~cm}^{-1}\right)$ and is probably indicative of the $\mathrm{NH}_{2}$ group substitution [62].
FTIR analysis is not conclusive but it is an indication of the chemical differences between the three synthesized chitosan derivatives. Besides, the different attained substitution degrees in these derivatives must be also taken in consideration: for example, CMC may have more probability to be di-substituted (which will increase the number of polymer carbonyl groups) [63] leading to higher interactions with $\mathrm{CO}_{2}$ and, consequently, to higher $\mathrm{CO}_{2}$ sorption and polymer swelling, contrarily to $\mathrm{CBC}$ and SCC. Because impregnation yields are also strongly dependent on these factors (sorption and swelling) this can be a possible explanation for the higher amounts of impregnated flurbiprofen observed for CMC when compared to CBC and SCC at the same operational impregnation conditions (see Table 1 and Fig. 4).

Table 2 shows the calculated values for diffusional kinetic constants $(k)$ and diffusional coefficients $(n)$ for the kinetics of flurbiprofen release from the three chitosan derivatives, as a function of operational impregnation pressure. The $n$ value is representative of the transportation mechanism and, for the studied systems, at $12 \mathrm{MPa}$, is higher for CMC followed by SCC and CBC (being 1.20, 0.86 and 0.57, respectively).

These values are in good agreement with the release curves presented at Fig. 4. All systems present a Non-Fickian behavior. Comparing the $n$ values, as a function of pressure for the $\mathrm{CMC}+$ flurbiprofen system, it is possible to observe an increase at 11 and $12 \mathrm{MPa}$, showing that, in some way, the impregnation operational pressure has influence on the system. The diffusional kinetic constant $(k)$, which usually defines the characteristics of a polymeric network system, is different for all polymers (at $12 \mathrm{MPa}$ ) and follows the order CMC $>\mathrm{CBC}>\mathrm{SCC}$ (around 1.8, 1.5 and 1.2, respectively). Higher diffusional kinetic constant values can be an indication of the existence of more favorable interactions between the polymer and the drug (flurbiprofen) in the physiological serum medium [31].

Fig. 7 shows drug release assays, at $313 \mathrm{~K}$ and at 9, 12 and $13 \mathrm{MPa}$, performed with and without drug release media (serum) renovation. The experiments with renovation of the drug release media with fresh serum $(1.6 \mathrm{ml})$ were done in order to simulate the in vivo eye conditions in terms of tear renovation, evaporation and drainage through the nasolacrimal system [8]. For 9 and $12 \mathrm{MPa}$, the difference (in terms of released mass) between the release experiments with serum renovation and without serum renovation was around $7 \%$, with a slightly increase for the begin-

Table 2

Flurbiprofen drug release kinetic parameters for impregnated samples at $40^{\circ} \mathrm{C}$ : $\mathrm{CMC}, \mathrm{CBC}$ and $\mathrm{SCC} ;(n)$ diffusion exponent and $(k)$ diffusion kinetic constant

\begin{tabular}{|c|c|c|c|c|c|c|c|c|c|}
\hline \multirow{3}{*}{$\begin{array}{l}\text { Impregnation process } \\
\text { SSI (MPa) }\end{array}$} & \multicolumn{9}{|c|}{ Polymers } \\
\hline & \multicolumn{3}{|c|}{$\mathrm{CMC}$} & \multicolumn{3}{|l|}{$\mathrm{CBC}$} & \multicolumn{3}{|l|}{ SCC } \\
\hline & $n$ & $k$ & $r^{2}$ & $n$ & $k$ & $r^{2}$ & $n$ & $k$ & $r^{2}$ \\
\hline 9.0 & 0.87 & 1.88 & 0.98 & - & - & - & - & - & - \\
\hline 10.0 & 0.64 & 1.49 & 0.98 & - & - & - & - & - & - \\
\hline 11.0 & 1.09 & 2.19 & 0.98 & - & - & - & - & - & - \\
\hline 12.0 & 1.20 & 1.79 & 0.99 & 0.57 & 1.52 & 0.99 & 0.86 & 1.19 & 0.98 \\
\hline 13.0 & 0.75 & 1.84 & 0.96 & - & - & - & - & - & - \\
\hline Soaking & 0.64 & 1.19 & 0.99 & - & _- & _- & - & - & - \\
\hline
\end{tabular}




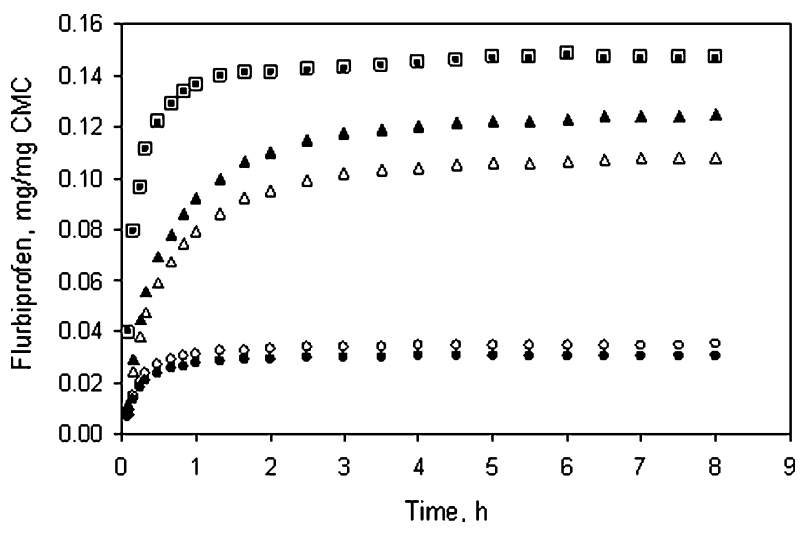

Fig. 7. Accumulated flurbiprofen mass released from CMC, impregnated at $40^{\circ} \mathrm{C}$ by SSI, with serum renovation (SR) and without serum renovation: $(\mathbf{O})$

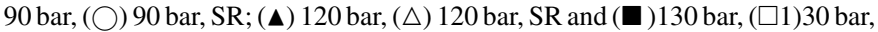
SR.

ning of the $12 \mathrm{MPa}$ release kinetics. At $13 \mathrm{MPa}$, the difference between the two drug release methodologies was around $0.8 \%$, for the first release point, and $0.1 \%$ for all the rest.

Fig. 8 shows the three chitosan derivatives surface observed by SEM before impregnation (I), after pressurization/treatment with $\mathrm{CO}_{2}$ (II) and impregnated with flurbiprofen by SSI
(III), at $12 \mathrm{MPa}$ and $313 \mathrm{~K}$. CMC shows a pattern of quasiparallel smooth sheets, in several layers, which seem to be just slightly changed after the $\mathrm{CO}_{2}$ treatment and also after the flurbiprofen impregnation. Before impregnation and $\mathrm{CO}_{2}$ treatment, CBC presents a kind of twisted flexible sheets pattern (in layers) and, after pressurization and impregnation, these sheets seem to become more twisted, like interlaced wires. Finally, SCC shows an interlaced wires pattern, which seems to become more interlaced after $\mathrm{CO}_{2}$ treatment and impregnation. These observations are a clear confirmation of the well known high pressure/supercritical $\mathrm{CO}_{2}$ plasticizing effect on the final morphological characteristics of these polymeric samples which, consequently, will influence their physical, mechanical and thermal properties. These effects (as well as others like induced crystallization) are already referred in the literature [41,42,64,65]. Finally, at Fig. 8, it is also possible to observe flurbiprofen's particles deposited on the surface of the chitosan derivatives. Despite the fact that only the deposited surface particles are visible, because the obtained drug release profiles and the notorious effect on samples' morphology (a strong indication that the $\mathrm{CO}_{2}+$ drug high pressure mixture swelled and plasticized these samples), we may presume that, with some confidence, flurbiprofen was also precipitated and impregnated into the three chitosan derivatives.
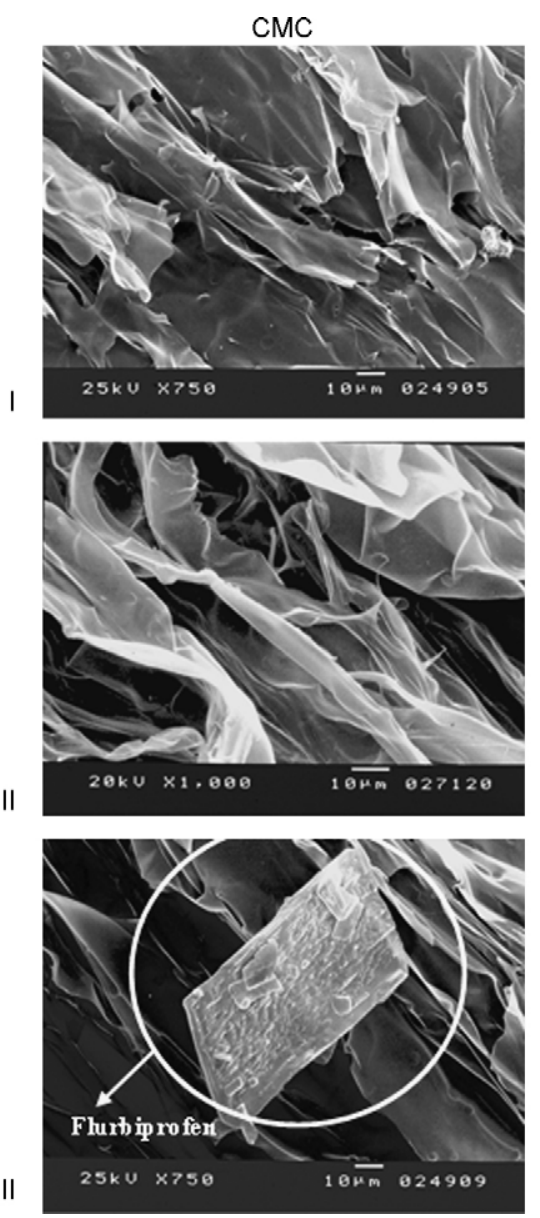
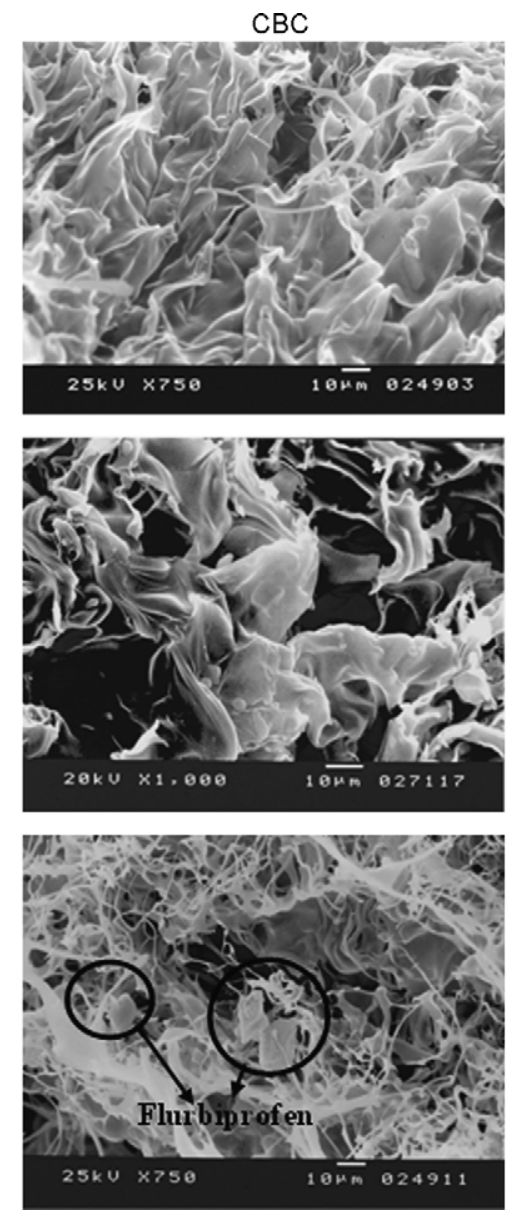
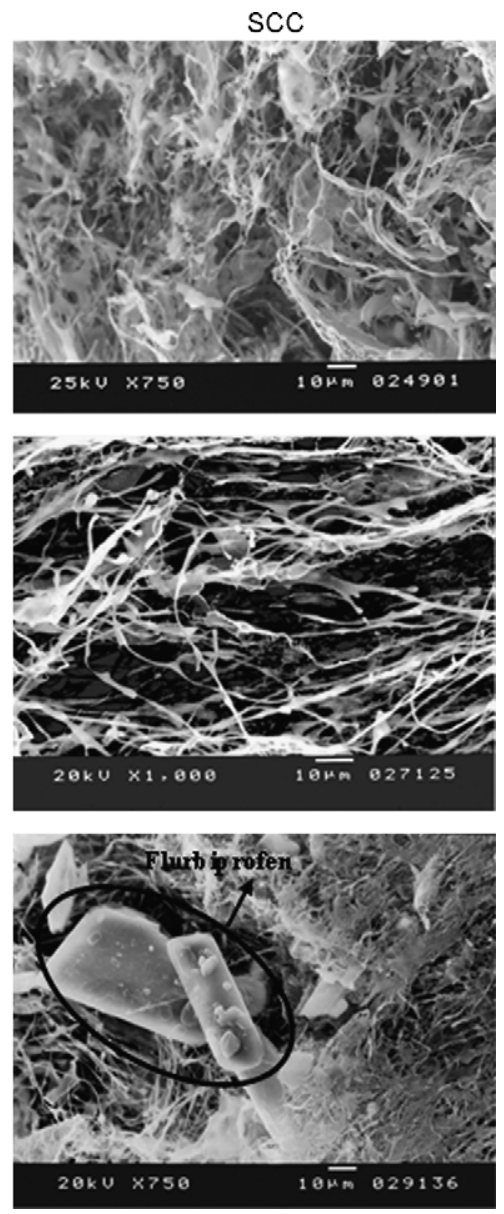

Fig. 8. Chitosan derivatives samples (CMC, $\mathrm{CBC}$ and SCC) observed by SEM before the impregnation (I); pressurized with $\mathrm{CO}_{2}$ (II) and impregnated with flurbiprofen by SSI (III), at $12 \mathrm{MPa}$ and $40^{\circ} \mathrm{C}$. 

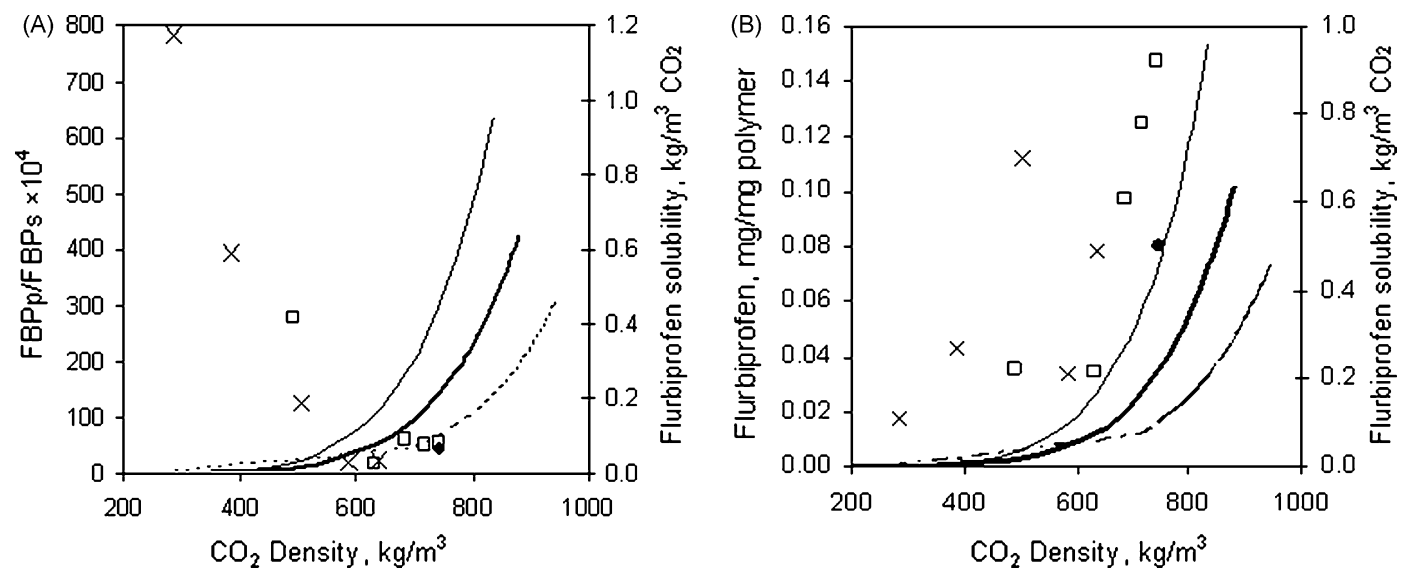

Fig. 9. (A) Flurbiprofen partition coefficient for $\mathrm{CMC}$ as a function of $\mathrm{CO}_{2}$ density. (B) Accumulated flurbiprofen mass released from $\mathrm{CMC}$ impregnated by $\mathrm{CO} 2$ SSI: (๑) $30^{\circ} \mathrm{C}$; $(\square) 40^{\circ} \mathrm{C}$ and $(\times) 50^{\circ} \mathrm{C}$. Flurbiprofen solubility in $\mathrm{CO}_{2}:(-) 30^{\circ} \mathrm{C}$; (一) $40^{\circ} \mathrm{C}$ and $(\cdots) 50^{\circ} \mathrm{C}$.

Fig. 9(A) shows the flurbiprofen/CMC partition coefficient as a function of $\mathrm{CO}_{2}$ density while Fig. 9(B) shows the accumulated flurbiprofen mass released (in absolute terms), also in function of $\mathrm{CO}_{2}$ density, at 303,313 and $323 \mathrm{~K}$. In both figures it is also represented the flurbiprofen's solubility in $\mathrm{CO}_{2}$ and, as expected, it is clear that the correlated flurbiprofen solubility in $\mathrm{CO}_{2}$ increases with the $\mathrm{CO}_{2}$ density for the three experimental solubility temperatures. Flurbiprofen is known to have a relatively high solubility in supercritical $\mathrm{CO}_{2}$ and the experimental flurbiprofen's solubility in supercritical $\mathrm{CO}_{2}$ was obtained and correlated by authors $[52,53,64,66]$. Fig. 9(A) shows that the flurbiprofen's partition coefficient (FBPp/FBPs ratio) decreases with the increase of the $\mathrm{CO}_{2}$ density. However, Fig. 9(B) shows that, in general terms and as expected, flurbiprofen absolute impregnated mass tends to increase with the $\mathrm{CO}_{2}$ density. This is due to above referred drug solubility increment and, probably, to the higher swelling and plasticizing effects promoted by high density supercritical (or liquid) supercritical carbon dioxide. We do not possess experimental data on these phenomena but they are recognized to be very common and important on these processes and are abundantly reported in literature $[65,67,69]$.

For example, at $303 \mathrm{~K}$ and $9 \mathrm{MPa}$, the drug + supercritical $\mathrm{CO}_{2}$ mixture is at a high pressure liquid state, which corresponds to a high density liquid state (thus promoting drug solubility in the high pressure phase). At the same pressure and at $313 \mathrm{~K}$, the polymer is in the presence of a high pressure supercritical phase in which $\mathrm{CO}_{2}$ densities are lower than at $303 \mathrm{~K}$ but higher than at $323 \mathrm{~K}$. As a consequence, flurbiprofen was impregnated in a smaller extent than at $303 \mathrm{~K}$ and in a higher extent than at $323 \mathrm{~K}$. However, this does not happen for all experimental pressures (for example at 11 and $12 \mathrm{MPa}$ ) which may indicate that other phenomena, and not just drug solubility, are involved in the process. In fact, the global impregnation process will always be the result of the relative specific interactions that may occur in the system: $\mathrm{CO}_{2}$-drug interactions (which controls drug solubility in $\mathrm{CO}_{2}$ ), polymer- $\mathrm{CO}_{2}$ interactions (which controls $\mathrm{CO}_{2}$ solubility in the polymer and, consequently, swelling and plasticization) and drug-polymer interactions (which controls solubility/compatibility of the drug in the polymer). Additionally, induced crystallization of the polymeric substrate can also influence the overall impregnation process. [65,67-69]. However, a reasonable approach is to consider that the operational $(P$ and $T)$ conditions will not affect the drug-polymer interactions as much as it will affect the two other possible interactions (the drug-polymer system - flurbiprofen/CMC was the same for all these represented systems and pressure and
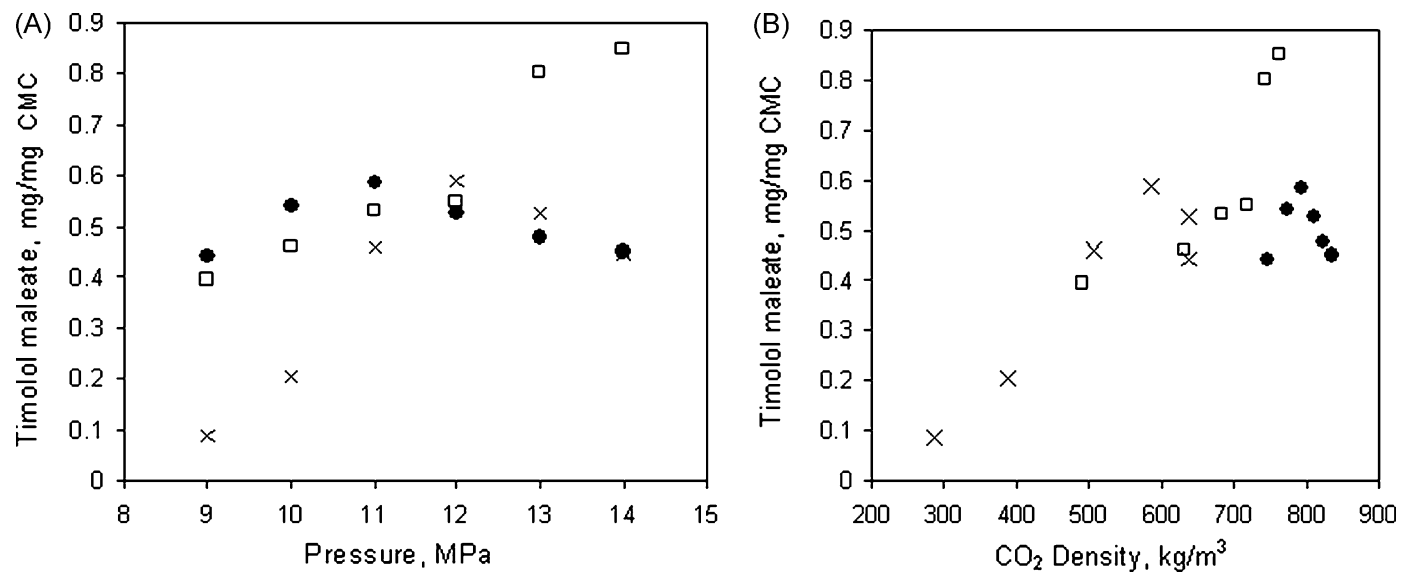

Fig. 10. Accumulated timolol maleate mass released from CMC impregnated by $\mathrm{CO}_{2}+\mathrm{EtOH}(5 \%$ mol) $\mathrm{SSI}$, as a function of pressure and $\mathrm{CO} 2$ density: $30{ }^{\circ} \mathrm{C}$ ( $\square$ ) $40^{\circ} \mathrm{C}$ and $(\times) 50^{\circ} \mathrm{C}$. 
temperature are not expected to strongly influence the specific interactions between these two solids). Thus, we may consider that, in fact, the predominant effects in the impregnation process may be the solubility of the drug in $\mathrm{CO}_{2}$ as well as the $\mathrm{CO}_{2}$ swelling and plasticizing effect on the polymers. On this type of polymers, induced crystallization by supercritical $\mathrm{CO}_{2}$ is not supposed to occur. Another important operational variable could be the system depressurization rate but it was kept constant for all studied systems.

So far, all the presented impregnated flurbiprofen amounts were determined by the drug release kinetics results (corresponding to the maximum of the released flurbiprofen accumulated mass). To verify these results, the amounts of impregnated flurbiprofen were also attempted to be quantified gravimetrically (weighing samples before and after impregnation experiments). However, experimentally, it was very difficult to measure gravimetrically these amounts because of the relatively low drug amounts involved and to the possibility of occurrence of some mass loss. This mass loss could be explained by the $\mathrm{CO}_{2}$ extraction of any chemicals (or of $\mathrm{CO}_{2}$ soluble low molecular weight polymeric chains) still present in the polymeric matrixes. Other explanation could be the removal of small solid polymer particles, pulled out of the system during depressurization. Flurbiprofen quantification by ion chromatography analysis also did not lead to satisfactory results because the very low flurbiprofen residual contents may induce high errors in results.

Fig. 10 shows the accumulated timolol mass released from $\mathrm{CMC}$, impregnated by SSI using $\mathrm{CO}_{2}+\mathrm{EtOH}$, as a function of operational pressure and of $\mathrm{CO}_{2}$ density. These results are also presented in Table 1. All release experiments were carried out with renovation of the drug release media. The highest impregnated amount of timolol maleate was attained at 313 and $14 \mathrm{MPa}$ (0.849 mg drug/mg polymer). For this system, and for all impregnation operational temperatures and pressures, after the two initial hours of drug release experiments (with serum renovation), the released mass of timolol maleate was found to be almost constant over time $(5-10 \mu \mathrm{g})$ for the next $6 \mathrm{~h}$ of release. As can be seen, just for the $313 \mathrm{~K}$ isotherm there is a general tendency for the maximum impregnated timolol maleate mass increase with the operational pressure and with the $\mathrm{CO}_{2}$ density. For 303 and $323 \mathrm{~K}$ isotherms, the impregnated mass increases with pressure and $\mathrm{CO}_{2}$ density, passes through a maximum (around $0.5-0.6 \mathrm{mg}$ of drug/mg of polymer) and then decreases.
A possible explanation is that, probably, at higher densities, the interactions between the solute and the mobile phase increased and are detrimental to the bonding forces between the solute and the polymeric matrix, thus leading to lower impregnation yields. But this did not occur for the $313 \mathrm{~K}$ isotherm. As already referred for the flurbiprofen system, the final partitioning of the solute between the mobile phase and the solid matrix will be the result of the relative strength of all binary interactions involved in the system. And, for timolol maleate, the high pressure mobile phase has an extra compound, the cosolvent (ethanol), thus increasing even more the system complexity. It is well known from literature that drug solubility in $\mathrm{CO}_{2}$ will increase when using a cosolvent with the same polar characteristics of the drug. It is also known that the same can happen with the polymer solubility in $\mathrm{CO}_{2}$ and the $\mathrm{CO}_{2}$ solubility in polymers. However, we do not have any information regarding these cosolvent effects on all the possible involved interactions that may be controlling the impregnation efficiency.

Fig. 11 shows the surface SEM micrographs of CMC impregnated with timolol maleate by SSI-CO + EtOH, at $303 \mathrm{~K}(\mathrm{~A})$, $313 \mathrm{~K}(\mathrm{~B})$ and $323 \mathrm{~K}(\mathrm{C})$, and at $12 \mathrm{MPa}$. As can be seen, there is a large amount of drug deposited at polymer surfaces. It also looks like the drug is "plasticized", forming films on the polymer surface. This can be due to a cosolvent (ethanol) effect on the deposition of drug particles during depressurization. Unfortunately, timolol maleate is almost insoluble in high pressure $\mathrm{CO}_{2}$ and we were unable to perform timolol impregnation experiments without the ethanol addition. Moreover, the presence of ethanol seems to have a strong influence on the amount of impregnated drug.

When we compare the relative amounts of released drugs (mg drug/mg polymer) between flurbiprofen and timolol maleate, Fig. 12(A) and (B), we can see that timolol maleate was impregnated in higher extents than flurbiprofen, despite the fact that it is much less soluble in $\mathrm{CO}_{2}$ than flurbiprofen [52,53]. For both drugs, it is also clear the already referred pressuredriven "tunable" character of the SSI method which constitutes an advantage over the soaking method.

Like in the CMC + flurbiprofen case, in this system the drug impregnated final mass will also be the result of the operational impregnation conditions and of the very complex relative specific interactions that may occur between all species present in the system: drugs, polymers, $\mathrm{CO}_{2}$ and, now a cosolvent

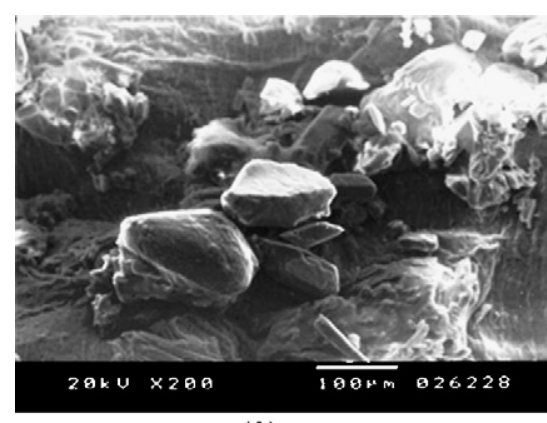

(A)

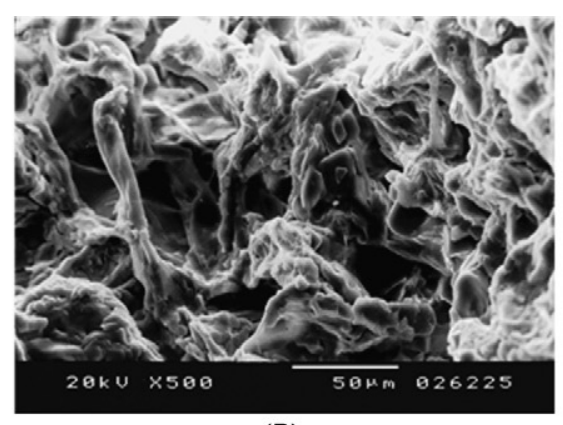

(B)

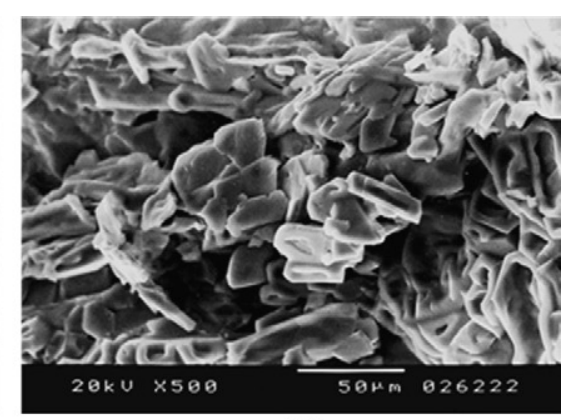

(C)

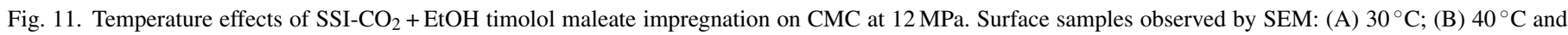
(C) $50^{\circ} \mathrm{C}$. 

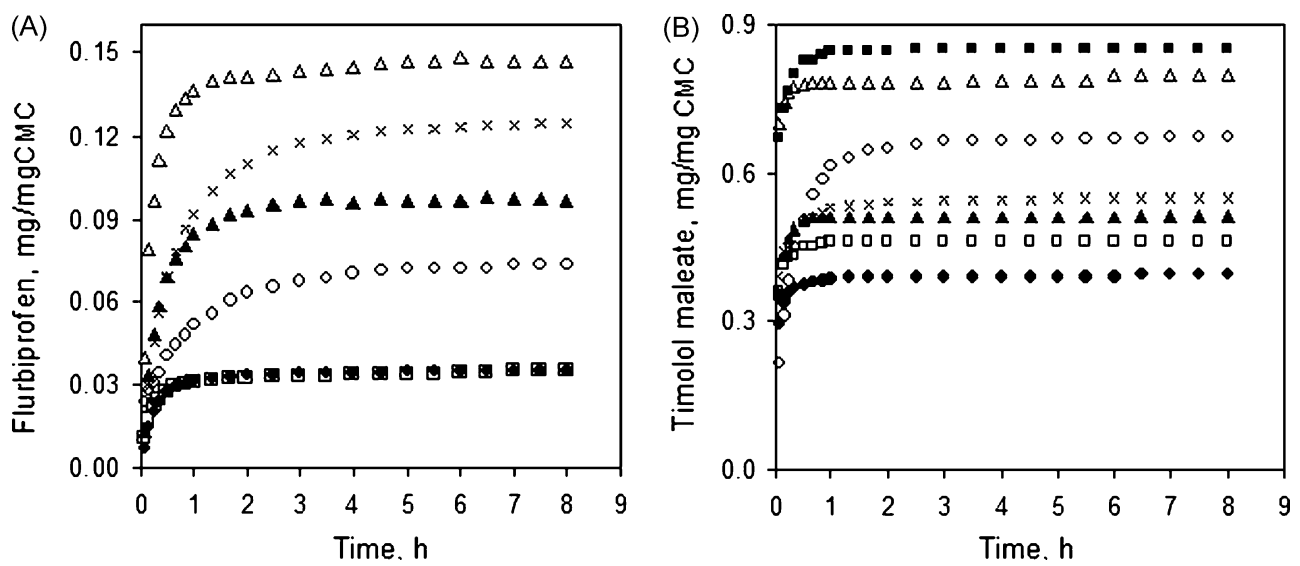

Fig. 12. Accumulated flurbiprofen (A) and timolol maleate (B) mass released from impregnated CMC SSI at $40{ }^{\circ} \mathrm{C}:(\bullet) 9 \mathrm{MPa} ;(\square) 10 \mathrm{MPa} ;(\boldsymbol{\Delta}) 11 \mathrm{MPa}$; $(\times) 12 \mathrm{MPa}$; $(\triangle) 13 \mathrm{MPa}$ and $(\mathbf{\square}) 14 \mathrm{MPa}$; and $(\bigcirc) \sim 0.1 \mathrm{MPa}$ soaking at $25^{\circ} \mathrm{C}$.

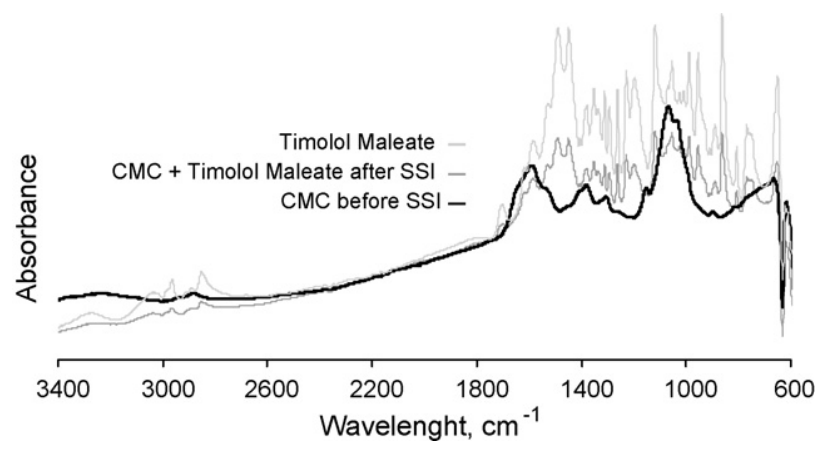

Fig. 13. FTIR analysis of timolol maleate $\mathrm{CO}_{2}+\mathrm{EtOH}(5 \%$ mol) SSI impregnated CMC: (-) CMC before SSI; (-) CMC + timolol maleate after SSI (at $313 \mathrm{~K}$ and $12 \mathrm{MPa}$ ) and $(\cdots)$ timolol maleate.

(ethanol). Thus, ethanol could be not just improving timolol maleate solubility in $\mathrm{CO}_{2}$ but also increasing the solubility of the high pressure phase (containing also $\mathrm{CO}_{2}$ and timolol maleate) in the $\mathrm{CMC}$ polymeric matrix, as well as improving the compatibility, swelling and plasticizing power of this phase.

Like for flurbiprofen impregnation, only the surface deposited particles/films are visible on micrographs. However, and due to the obtained drug release profiles and to the notorious swelling and plasticizing effects observed on polymeric samples' morphology, in this case we may consider that timolol maleate was also precipitated and impregnated inside the three chitosan derivatives. Samples loaded with timolol maleate were also analyzed by FTIR and, in Fig. 13, it is possible to observe the two spectra profiles, corresponding to the polymer (CMC) with and without impregnated drug. The individual FTIR spectrum for timolol maleate confirmed this result. Furthermore, sulphur quantification (performed by ion chromatography analysis) permitted to quantify the amount of timolol maleate still present in the polymeric matrix after the drug release experiments in physiological serum $(1.54 \pm 0.32 \%$ of total impregnated mass, with $98.46 \pm 0.32 \%$ of total released drug mass).

\section{Conclusions}

In this work three chitosan derivatives ( $N$-carboxymethyl chitosan, $N$-carboxybutyl chitosan and $N$-succinyl chitosan) were impregnated with flurbiprofen and timolol maleate, using a SSI technique (and employing high pressure $\mathrm{CO}_{2}$ and $\mathrm{CO}_{2}+\mathrm{EtOH}$ mixtures) in order to try to develop hydrogel-type ophthalmic drug release systems. Impregnation experiments were carried out from 9.0 up to $14.0 \mathrm{MPa}$, and at $303.0,313.0$ and $323.0 \mathrm{~K}$. The resulting polymeric drug delivery systems, as well as other polymeric samples processed in $\mathrm{CO}_{2}$, were characterized by FTIR spectroscopy and Scanning Electron Microscopy (SEM). Drug release kinetics studies were performed for all prepared systems. The effects of impregnation pressure and temperature on the release kinetics results were studied and compared to the traditional soaking impregnation method.

For the same operational conditions, results confirmed that, as expected, the three different (chemically and physically) polymeric structures conditioned the impregnation and the drug release processes. Furthermore, and even though the final impregnated drug mass is always the result of the employed operational impregnation conditions and of the very complex relative specific interactions that may occur between all species present in the system (drugs, polymers, $\mathrm{CO}_{2}$ and ethanol), results showed that, for $N$-carboxymethyl chitosan, the predominant effects in the impregnation process seemed to be the solubility of drugs in $\mathrm{CO}_{2}$ and in $\mathrm{CO}_{2}+\mathrm{EtOH}$ mixtures, as well as the swelling and plasticizing effect of $\mathrm{CO}_{2}$ and ethanol on the polymer. Finally, the SSI method proved to be a more efficient and "tunable" impregnation process than the traditional impregnation of drugs by a soaking method.

Therefore, and using this "tunable" SSI method, these $N$ chitosan derivatives-based ophthalmic drug delivery systems can be easily and efficiently prepared taking in consideration the desired drug levels according to patients needs.

\section{Acknowledgments}

This work was financially supported by FCT-MCES, FEDER, Portugal (POCTI/FCB/38213/2001). Dr. M. E. M. Braga acknowledges FCT-MCES for the postdoctoral fellowship (SFRH/BPD/21076/2004). 


\section{References}

[1] A.F. Clark, T. Yorio, Ophthalmic drug discovery, Nat. Rev. Drug Discov. 2 (2003) 448-459.

[2] C. Le Bourlais, L. Acar, H. Zia, P.A. Sado, T. Needham, R. Leverge, Ophthalmic drug delivery systems, Recent Adv. Prog. Retin. Eye Res. 17 (1) (1998) 33-58.

[3] H. Sasaki, K. Yamamura, K. Nishida, J. Nakamura, M. Ichikawa, Delivery of drugs to the eye by topical application, Prog. Retin. Eye Res. 15 (1996) 583-619.

[4] S. Ding, Recent developments in ophthalmic drug delivery, Pharm. Sci. Technol. To. 1 (1998) 328-335.

[5] R. Langer, Drug delivery and targeting, Nature 392 (1998) 5-10.

[6] B.J. Aungst, Novel formulation strategies for improving oral bioavailability of drugs with poor membrane permeation or presystemic metabolism, J. Pharm. Sci. 82 (1993) 979-987.

[7] A. Urtti, L. Salminen, Drug delivery approaches to minimize systemic concentrations of ocularly administered drugs, Surv. Ophthalmol. 37 (1993) $435-456$.

[8] V. Baeyens, R. Gurny, Chemical and physical parameters of tears relevant for the design of ocular drug delivery formulations, Pharm. Acta Helv. 72 (1997) 191-202.

[9] V.P. Costa, A. Harris, E. Stefansson, J. Flammer, G.K. Krieglstein, N. Orzalesi, A. Heijl, J.-P. Renard, L.M. Serra, The effects of antiglaucoma and systemic medications on ocular blood flow, Prog. Retin. Eye Res. 22 (2003) 769-805.

[10] J.W. Shell, Pharmacokinetics of topically applied ophthalmic drugs, Surv. Ophthalmol. 26 (1982) 207-218.

[11] M. Patrick, A.K. Mitra, Overview of ocular drug delivery and iatrogenic ocular cytopathologies, in: A.K. Mitra (Ed.), Ophthalmic Drug Delivery Systems, Marcel Dekker Inc., New York, 1993, pp. 1-27.

[12] I.K. Reddy, M.G. Ganesan, Ocular therapeutics and drug delivery: an overview, in: I.K. Reddy (Ed.), Ocular Therapeutics and Drug Delivery: a Multidisciplinary Approach, Technomic Publishing Company Inc., Philadelphia, USA, 1996, pp. 3-29.

[13] M.N.V.R. Kumar, A review of chitin and chitosan applications, React. Funct. Polym. 46 (2000) 1-27.

[14] V. Dodane, V. Vilivalam, Pharmaceutical applications of chitosan, Pharm. Sci. Technol. To. 1 (1998) 246-253.

[15] R.T. Pijls, T. Sonderkamp, G.W. Daube, R. Krebber, H.H.L. Hanssen, R.M.M.A. Nuijts, L.H. Koole, Studies on a new device for drug delivery to the eye, Eur. J. Pharm. Biopharm. 59 (2005) 283-288.

[16] P. Gupta, K. Vermani, S. Garg, Hydrogels: from controlled release to $\mathrm{pH}-$ responsive delivery, Drug Discov. Today 7 (2002) 569-579.

[17] C.L. Christie, Therapeutic Contact Lenses, Contact Lens Ant. Eye 22 (1999) S20-S25.

[18] M.R. Jain, Drug delivery through soft contact lenses, Brit. J. Ophthalmol. 72 (1988) 150-154.

[19] A.W. Lloyd, R.G.A. Faragher, S.P. Denyer, Ocular biomaterials and implants, Biomaterials 22 (2001) 769-785.

[20] N.A. Peppas, P. Bures, W. Leobandung, H. Ichikawa, Hydrogels in pharmaceutical formulations, Eur. J. Pharm. Biopharm. 50 (2000) $27-$ 46.

[21] J. Berger, M. Reist, J.M. Mayer, O. Felt, R. Gurny, Structure and interactions in chitosan hydrogels formed by complexation or aggregation for biomedical applications, Eur. J. Pharm. Biopharm. 57 (2004) 3552.

[22] L.L. Lloyd, J.F. Kennedy, P. Methacanon, M. Paterson, C.J. Knill, Carbohydrate polymers as wound management aids, Carbohyd. Polym. 37 (1998) 315-322.

[23] H. Dureja, A.K. Tiwary, S. Gupta, Simulation of skin permeability in chitosan membranes, Int. J. Pharma. 213 (2001) 193-198.

[24] X. Zhao, K. Kato, Y. Fukumoto, K. Nakamae, Synthesis of bioadhesive hydrogels from chitin derivatives, Int. J. Adhes. Adhes. 21 (2001) 227-232.

[25] I. Henriksen, S.R. Våagen, S.A. Sande, G. Smistad, J. Karlsen, Interactions between liposome and chitosan II: Effect of selected parameters on aggregation and leakage, Int. J. Pharma. 146 (2) (1997) 193-203.
[26] O. Felt, P. Furrer, J.M. Mayer, B. Plazonnet, P. Buri, R. Gurny, Topical use of chitosan in ophthalmology: tolerance assessment and evaluation of precorneal retention, Int. J. Pharma. 180 (1999) 185-193.

[27] T.M.D. Yasukawa, H. Kimura, Y. Tabata, Y. Ogura, Biodegradable scleral plugs for vitreoretinal drug delivery, Adv. Drug Deliver. Rev. 52 (2001) $25-36$.

[28] G. Sandri, S. Rossi, F. Ferrari, M.C. Bonferoni, C. Muzzarelli, C Caramella, Assessment of chitosan derivatives as buccal and vaginal penetration enhancers, Eur. J. Pharma. Sci. 21 (2004) 351-359.

[29] M. Thanou, M.T. Nihot, M. Jansen, J.C. Verhoef, H.E. Junginger, Mono$N$-carboxymethyl chitosan (MCC), a Polyampholytic chitosan derivative, enhances the intestinal absorption of low molecular weight heparin across intestinal epithelia in vitro and in vivo, J. Pharma. Sci. 90 (2001) 38-46.

[30] M. Thanou, J.C. Verhoef, H.E. Junginger, Oral Drug absorption enhancement by chitosan and its derivatives, Adv. Drug Deliver. Rev. 52 (2001) $117-126$.

[31] Z. Aiping, L. Jianhong, Y. Wenhui, Effective loading and controlled release of camptothecin by $O$-carboxymethylchitosan aggregates, Carbohyd. Polym. 63 (2006) 89-96.

[32] K.S.C.R. Dos Santos, H.S.R.C. Silva, E.I. Ferreira, R.E. Bruns, $3^{2}$ Factorial design and response surface analysis optimization of $\mathrm{N}$ carboxybutylchitosan synthesis, Carbohyd. Polym. 59 (2005) 37-42.

[33] Y. Kato, H. Onishi, Y. Machida, $N$-succinyl-chitosan as a drug carrier: water-insoluble and water-soluble conjugates, Biomaterials 25 (2004) 907-915.

[34] M. Graziacascone, Z. Zhu, F. Borselli, L. Lazzeri, Poly(vinyl alcohol) hydrogels as hydrophilic matrices for the release of lipophilic drugs loaded in PLGA nanoparticles, J. Mater. Sci-Mater. M. 13 (2002) 29-32.

[35] J.H. Ward, N.A. Peppas, Preparation of controlled release systems by freeradical UV polymerizations in the presence of a drug, J. Control. Release 71 (2001) 183-192.

[36] J. Elisseeff, W. McIntosh, K. Anseth, S. Riley, P. Ragan, R. Langer, Photoencapsulation of chondrocytes in poly(ethylene oxide)-based semiinterpenetrating networks, J. Biomed. Mater. Res. 51 (2000) 164-171.

[37] D. Gulsen, A. Chauhan, Dispersion of microemulsion drops in HEMA hydrogel: a potential ophthalmic drug delivery vehicle, Int. J. Pharm. 292 (2005) 95-117.

[38] D. Ogomi, T. Serizawa, M. Akashi, Controlled release based on the dissolution of a calcium carbonate layer deposited on hydrogels, J. Control. Release 103 (2005) 315-323.

[39] S.H. Gehrke, L.H. Uhden, J.F. McBride, Enhanced loading and activity retention of bioactive proteins in hydrogel delivery systems, J. Control. Release 55 (1998) 21-33.

[40] O.S. Fleming, S.C. Kazarian, Polymer Processing with Supercritical Fluids, in: M.F. Kemmere, T. Meyer (Eds.), Supercritical Carbon Dioxide: in Polymer Reaction Engineering, Wiley-VCH Verlag GmbH \& Co, Weinheim, Germany, 2005, pp. 205-234.

[41] F. Kikic, F. Vecchione, Supercritical Impregnation of Polymers, Curr. Opin. Solid St. Mat. Sci. 7 (2003) 399-405.

[42] S.G. Kazarian, Polymer Processing with Supercritical Fluids, Polym. Sci. Ser. C 42 (1) (2000) 78-101.

[43] N. Elvassore, I. Kikic, Pharmaceutical processing with supercritical fluids, in: A. Bertucco, G. Vetter (Eds.), High Pressure Process Technology: Fundamentals and Applications, 9, Industrial Chemistry Library, Elsevier, Amsterdam, The Netherlands, 2001, pp. 612-625.

[44] K. Westesen, H. Bunjes, M.H.J. Koch, Physicochemical characterization of lipid nanoparticles and evaluation of their drug loading capacity and sustained release potential, J. Control. Release 48 (1997) 223-236.

[45] S.G. Kazarian, G.G. Martirosyan, Spectroscopy of polymer/drug formulations processed with supercritical fluids: in situ ATR-IR and Raman study of impregnation of ibuprofen into PVP, J. Control. Release 232 (2002) $81-90$.

[46] T.F. Vandamme, L. Brobeck, Poly(amidoamine) dendrimers as ophthalmic vehicles for ocular delivery of pilocarpine nitrate and tropicamide, J. Control. Release 102 (2005) 23-38.

[47] K. Gong, J.A. Darr, I.U. Rehman, Supercritical fluid assisted impregnation of indomethacin into chitosan thermosets for controlled release applications, Int. J. Pharma. 315 (2006) 93-98. 
[48] A.C. Duarte, T. Casimiro, A. Aguiar-Ricardo, A. Simplício, C.M.M. Duarte, Supercritical fluid polymerization and impregnation of molecularly imprinted polymers for drug delivery, J. Supercrit. Fluid 39 (1) (2006) 102-106.

[49] M. Moneghini, I. Kikic, B. Perissutti, E. Franceschinis, A. Cortesi, Characterization of nimesulide-betacyclodextrins systems prepared by supercritical fluid impregnation, Eur. J. Pharma. Biopharma. 58 (2004) 637-644.

[50] D. Aggarwal, I.P. Kaur, Improved pharmacodynamics of timolol maleate from a mucoadhesive noisomal ophthalmic drug delivery system, Int. J. Pharma. 290 (2005) 155-159.

[51] R. Pignatello, C. Bucolo, G. Spedalieri, A. Maltese, G. Puglisi, Flurbiprofen-loaded acrylate polymer nanosuspensions for ophthalmic application, Biomaterials 23 (2002) 3247-3255.

[52] A.R.C. Duarte, P. Coimbra, H.C. De Sousa, C.M.M. Duarte, Solubility of flurbiprofen in supercritical carbon dioxide, J. Chem. Eng. Data 49 (2004) 452-499.

[53] P. Coimbra, A.R.C. Duarte, H.C. De Sousa, C.M.M. Duarte, Solubility of flurbiprofen and timolol maleate in dense carbon dioxide, in: Proceedings of the sixth International Symposium on Supercritical Fluids (ISASF), Brunner, G., Kikic, I., Perrut, M., (Eds.), Versailles, France, Tome 2, 775-780, April 28-30, 2003.(ISBN2-905-267-37-02).

[54] M. Mariz, MSc Thesis, University of Coimbra, Portugal, 1999.

[55] US Food and Drug Administration-FDA, accessed 2006/06/30 (http://www.fda.gov/cder/Offices/OPS_IO/MRTD.htm\#F).

[56] H. S. R. C. Silva, Antimaláricos potenciais: Pró-fármacos poliméricos e formas de liberação controlada de artemisinina. Faculdade de Ciências Farmacêuticas - Universidade de São Paulo, São Paulo. PHD Thesis, 2006.

[57] H.J. Cipriano de Sousa, M.H. Mendes Gil, C.M. Martins Duarte, E.O. Baptista Leite, Cruz Duarte, A.R. Method for preparing sustained-release therapeutic ophthalmic articles using compressed fluids for impregnation of drugs, European Patent EP 1611877 A1, April 012006.

[58] H.C. De Sousa, A.R.C. Duarte, J.P. Guerra, V.P. Costa, E.O.B. Leite, C.M.M. Duarte, M.H. Gil, Development of Therapeutic Contact Lenses Using Supercritical Fluids, in: Proceedings of the seventh International
Symposium on Supercritical Fluids - ISSF2005, Orlando, FL, USA, May, $1-4,2005$.

[59] X.Y. Xiong, K.C. Tam, L.H. Gan, Release kinetics of hydrophobic and hydrophilic model drugs from pluronic F127/poly(lactic acid) nanoparticles, J. Control. Release 103 (2005) 73-82.

[60] G. Hsiue, J. Guu, C. Cheng, Poly(2-hydroxyethyl methacrylate) film as a drug delivery system for pilocarpine, Biomaterials 22 (2001) 17631769.

[61] C. Alvarez-Lorenzo, H. Hiratani, J.L. Gómez-Amoza, R. MartínezPacheco, C. Souto, A. Concheiro, Soft contact lenses capable of sustained delivery of timolol, J. Pharma. Sci. 91 (2002) 2182-2190.

[62] N.P.G. Roeges, Guide to the Complete Interpretation of Infrared Spectra of Organic Structures, Wiley, England, 1994.

[63] P. le Dung, M. Milas, M. Rinaudo, J. Desbrieres, Water soluble derivatives obtained by controlled chemical modifications of chitosan, Carbohyd. Polym. 24 (1994) 209-214.

[64] H. Zhou, L. Fang, J. Yang, X. Xie, Effect of the supercritical $\mathrm{CO}_{2}$ on surface structure of PMMA/PS blend thin films, J. Supercrit. Fluid. 26 (2003) 137-145.

[65] A.R. Berens, G.S. Huvard, R.W. Korsmeyer, F.W. Kunlg, Application of compressed carbon dioxide in the incorporation of additives into polymers, J. Appl. Polym. Sci. 46 (1992) 231-237.

[66] P. Coimbra, C.M.M. Duarte, H.C. De Sousa, Cubic equation-of-state correlation of the solubility of some anti-inflammatory drugs in supercritical carbon dioxide, Fluid Phase Equilibr. 239 (2005) 188-199.

[67] Q. Xu, Y. Chang, Complex interactions among additive/supercritical $\mathrm{CO}_{2}$ /polymer ternary systems and factors governing the impregnation efficiency, J. Appl. Polym. Sci. 93 (2004) 742-748.

[68] A.R. Duarte, A.L. Simplicio, A. Vega-Gonzalez, P. Subra-Paternault, P. Coimbra, M.H. Gil, H.C. de Sousa, C.M.M. Duarte, Supercritical fluid impregnation of a biocompatible polymer for ophthalmic drug delivery, J. Supercrit. Fluid. 42 (2007) 373-377.

[69] P.D. Condo, S.R. Sumpter, M.L. Lee, K.P. Johnston, Partition coefficients and polymer-solute interaction parameters by inverse supercritical fluid chromatography, Ind. Eng. Chem. Res. 35 (1996) 1115-1123. 